\section{artelogie}

\section{Artelogie}

Recherche sur les arts, le patrimoine et la littérature de l'Amérique latine

$8 \mid 2016$

Transgression dans les arts / transgression des arts

\title{
Entrevista com Olgária Matos
}

\section{Gaspar Paz e Aline Miklos}

\section{OpenEdition \\ Journals}

\section{Edição electrónica}

URL: http://journals.openedition.org/artelogie/455

DOI: $10.4000 /$ artelogie.455

ISSN: 2115-6395

\section{Editora}

Association ESCAL

\section{Refêrencia eletrónica}

Gaspar Paz e Aline Miklos, « Entrevista com Olgária Matos », Artelogie [Online], 8 | 2016, posto online no dia 26 janeiro 2016, consultado o 15 setembro 2020. URL : http://journals.openedition.org/ artelogie/455

Este documento foi criado de forma automática no dia 15 setembro 2020.

Association ESCAL 


\title{
Entrevista com Olgária Matos
}

\author{
Gaspar Paz e Aline Miklos
}

Nas artes e na filosofia o ato transgressivo pode ser vivenciado por meio da crítica à normatividade, à hierarquia dos valores e à interdição; bem como, pela constatação dos limites de nossa própria linguagem. Em sua opinião, quais são os questionamentos que a experiência da transgressão pode nos propiciar hoje? E, mais especificamente, o que as artes e a política nos revelam sobre essa experiência?

$\mathrm{Na}$ tradição das artes, cada época ou formação cultural cria sua própria normatividade como sentido e orientação da sensibilidade e do pensamento. A partir pelo menos de Kant e do fim dos cânones nas artes, neutraliza-se, de certa maneira, a ideia de vanguarda, até porque uma vanguarda quando é realmente vanguarda, tem força própria de surpreender e transformar valores, e se torna um clássico. Com Kant, há o "livre jogo das faculdades", sem hierarquias entre a sensibilidade, o entendimento e a razão, onde o juízo estético baseia-se na subjetivação do gosto, e o objeto artístico é dispensado de identidade própria. A representação, a mímesis é substituída pela expressão, a arte como experiência cede à "experiência" como arte. Assim, sob o impacto da indústria cultural, estabelece-se a indiferenciação entre bom gosto e mau gosto, "cultura de elite" e "cultura popular" - clivagem esta produzida pela própria indústria da cultura. Que se pense em Mozart em ritmo de samba que não é nem Mozart, nem samba, mas, nas palavras de Adorno, uma "barbárie estilizada". No reino da indiferenciação, desaparece o sentimento do sublime, a arte não é mais "desinteressada", tornando-se apenas "interessante". Sob a indústria cultural chocar se tornou uma norma e, assim, a transgressão como experiência das épocas criativas se converteu em obrigatoriedade: Yves Klein e suas "Antropometrias" com sangue de animais e sua assinatura com seu próprio sangue. Ou Orlan e suas cirurgias plásticas, fazendo do próprio corpo o suporte das lacerações; ou a utilização de cinzas de uma incineração nas telas, ou as fezes enlatadas, ou os cadáveres estetizados e plastificados, ou performances do aniquilamento da vida do jovem pintor japonês que se suicida jogando-se do alto de um prédio sobre uma tela colocada na rua, convertida em obra póstuma pela doação da tela ensanguentada ao Museu de Arte de Tóquio. Isso significa o fim da autonomia 
das artes e sua subsunção ao status quo do "politicamente correto", traduzido para o universo estético.

Recentemente, Scarlett Marton analisou o pensamento rebelde e transgressivo de autores como Foucault, Deleuze e Derrida (Café filosófico https://www.youtube.com/watch? $v=e 9 f T D r V e 7 d Q)$. Poderíamos acrescentar a essa lista Blanchot e Bataille. Como você avalia as reverberações desses autores na América Latina?

Esses pensadores, como todo pensamento rigoroso, são livres na interpretação e invenção de conceitos filosóficos em suas análises do presente, Foucault e sua arqueologia dos saberes e genealogia, Deleuze e seus rizomas, Derrida e sua desconstrução, Blanchot e os dilaceramentos da ambiguidade, Bataille e o erotismo e a morte. Na América Latina, correndo o risco das generalizações, esses filósofos, críticos das identidades fixas, foram incorporados no "direito à diferença" e a relatividade das culturas caiu em relativismo, uma vez que o "universal" como referência simbólica, como dimensão "externa" desapareceu, restando o enfrentamento direto entre grupos identitários, cada um fechado sobre si mesmo. Na modernidade e seu frenesi da tábula rasa, nunca se rompeu tanto com o passado, mas e, ao mesmo tempo, se busca pertencimentos identitários potencialmente segregadores entre si.

Se interpretarmos a herança da desconstrução derridiana como transgressiva, que consequências poderíamos pensar no que concerne à América Latina? Nesse sentido, teríamos que considerar todo um contexto histórico de colonização, de preconceitos e políticas de dominação para com os indígenas e os africanos. O que achas?

A desconstrução derridiana é, principalmente, a recusa dos extremos e das bruscas rupturas entre conceitos, acontecimentos, fronteiras, etc, pois é o pensamento das diferenças diferidas. Nesse sentido, sempre há abertura e incompletude, "decisão". Quer dizer que quando se decide por algo, isso significa que há algo que permanece como um possível, como rastro ou fantasma. Dessa forma, o dualismo de identidade e alteridade, colonizador e colonizado, Europa e África, Oriente e Ocidente são sujeitos a desconstruções, porque essas oposições supõem tomar cada um dos termos como sendo portadores de uma origem, quando tudo é misturado, misto, mestiço, com suas intensidades e diferenciações. Assim, penso não desnaturar demais o pensamento de Derrida se disser que é preciso admirar o que é admirável em cada cultura e recusar o que é abominável, não existindo dualismo entre utopia e realismo, pois há traços realistas na utopia e traços utópicos no realismo.

Poderíamos dizer que tais discrepâncias nos impelem a uma transgressão que nos leva em direção a uma nova descoberta do sensível, da sensibilidade? Uma espécie de descolonização do pensamento?

Penso que a noção de "descolonização do pensamento" traz consigo um estereótipo segundo o qual os países "periféricos" teriam sofrido a imposição violenta da cultura europeia e assim teríamos perdido nossa "identidade". Neste aspecto Derrida e Haroldo de Campos são os pensadores de uma heterofilia congênita das artes, das línguas e culturas. Assim como o Estado tende a confiscar a cultura para seus fins de dominação, criando estereótipos do "colonizado", é preciso cuidar para não criarmos também estereótipos da cultura ocidental de que descendemos. Para ser breve, a cultura ocidental foi a do generoso humanismo de um Montaigne - para quem "um homem é todos os homens", pois todos nós somos páginas de um mesmo livro espalhadas pelo mundo. Mas também essa cultura resultou em uma civilização técnica, lembrando que de uma maneira ou outra, todas as grandes descobertas 
científicas a partir do Renascimento foram "europeias", americanas ou de um modo geral "ocidentais". A cultura europeia, antes idealizada, foi perdendo sua potência de atração em particular depois das guerras que o continente europeu conheceu. A "culpabilidade" europeia foi abrindo espaço para que culturas antes consideradas subalternas pudessem reivindicar sua superioridade diante do "colonizador".

Há alguma circunstância sociocultural ou experiência artística latino-americana que tenha Ihe chamado atenção nesse sentido?

A América-Latina tem seus grandes autores que são universais em sua singularidade, como Huidobro no Chile, Amado Nervo no Uruguai, César Valejo no Peru, para não falar de Borges, etc. A arte desconhece fronteiras espaciais e temporais e assim ela dialoga antes de tudo com a própria arte.

Neste caso a transgressão seria uma espécie de saturação diante de situações limites? E quais seriam as consequências disso? Ímpetos novos de expressão e criatividade ou suspensão dos acontecimentos?

Quando a transgressão se torna um protocolo, ela acaba tendo muito studium e nenhum punctum, quer dizer, sua sprezzatura, as intenções do autor ficam explícitas demais, ou melhor, o autor não nos deixa nada para sentir, a obra já designa o que é para ser sentido e pensado.

A partir dos termos estetização da vida e politização da estética poderíamos pensar na potencialização da ideia de transgressão, já que tendências artísticas se nutrem de padrões sexuais, hábitos de comportamento, formas de relacionamento, contrastes econômicos, políticos e ideológicos?

Penso que a força da arte está em retirar o estético do político mais que politizar a arte, instrumentalizando-a, convertendo-a em ideologia a serviço de alguma causa particular. Essa grandeza de extrair do político o estético está representada, por exemplo, na arte moderna do Japão que da bomba atômica inventou o Butô.

Em sua opinião isso implicaria a reflexão sobre a mudança desses padrões ? Neste caso, a transgressão seria um impulso de transformação, um princípio de contestação, como diria Blanchot?

A ideia de transgressão supõe o reconhecimento de limites e a deliberação de romper com eles ou "jogar" com eles. Assim, nossa cultura sendo a da "ilimitação", em que não há mais diferenciação clara entre o proibido e o consentido, em que nada é pornográfico porque tudo tende a sê-lo - pornográfico não no sentido da exposição literal do sexo, mas da exibição do mais íntimo, do mais "próprio", do mais secreto -, não poderia ser transgressiva. Não por acaso, quase que desapareceram no contemporâneo o pudor e a timidez.

Renato Janine Ribeiro lançou um questionamento interessante sobre o assunto, dizendo que "A transgressão não é mais o que era". Usando como referência as artes visuais e a literatura, entre meados do século XIX e as décadas de 1960 e 1970, o autor sublinha que o impacto e as consequências da transgressão nesses períodos foram extremamente contundentes. Autores como Flaubert, Baudelaire, Lawrence, Duchamp enfrentaram críticas, censuras ou processos, acusados de violação de leis ou da moral vigente, visto que suas obras incitavam uma intensa reviravolta nos valores da época. Contudo, para Janine Ribeiro, tal cenário se alterou fortemente em nossos dias e $\mathrm{o}$ ato de transgredir tornou-se mais complexo e difícil, em razão de uma maior aceitação do diferente e do dissidente. Contrabalançando seus argumentos com dados da atualidade, o autor avaliou as consequências da transgressão no plano social e ético, através da análise de situações recentes, como um escândalo envolvendo o diretor de teatro Gerald Thomas ou a 
condenação a 15 anos de prisão do poeta Mohammad al-Ajami por causa do conteúdo de um de seus poemas. Qual sua opinião sobre tais argumentos?

Penso que uma das características das sociedades dominadas pela tecnologia e pela economia de mercado a ela associada, é que a tecnologia acelera o tempo, enquanto que o mercado, ingressando em todas as esferas da sociedade, resulta em uma cultura que Nietzsche denominou "filisteia". o "filisteu cultivado" é aquele que conhece o preço de todas as coisas, mas desconhece seu valor. As mudanças sociais e culturais sendo incessantes - nos modos de vida, comportamentos, instituições, valores - não deixam mais espaço para criar ou reconhecer valores, uma vez que estes necessitam duração no tempo. Os comportamentos se modificam velozmente antes que novos valores que os acompanhariam tenham podido se formar. Por isso nosso mundo é anti-ético. Nas palavras de Nietzsche, trata-se do niilismo, pois os valores perdem todo valor, como o de indivíduo, identidade, liberdade, verdade, sentido, finalidade, ética, política, religião, história que eram o horizonte da época pré-tecnológica. A "era da técnica" aboliu aquele cenário humanista e se dissipou o sentido das coisas, pois a técnica não tende a nenhum fim nem promove sentidos, nem desvela alguma verdade. Ela simplesmente funciona.

Em sua produção ensaística, refletiste sobre a poesia de Baudelaire, destacando elementos transgressivos na linguagem do autor de As Flores do Mal. Temas como a transformação da cidade (spleen de Paris), o esgotamento do desejo são evidências que impactam o plano sociocultural, desafiando e subvertendo cânones históricos. Poderíamos pensar tais contrastes em relação ao panorama contemporâneo, sublinhando impasses e interrogando suas dimensões estéticas e éticas?

Penso que Baudelaire é o autor inaugural porque foi um dos primeiros a tematizar que a modernidade nasceu de um trauma - o da Revolução Francesa - no sentido em que se perderam a um só tempo a transcendência religiosa (a revolução se dizia ateia), política (deposição do Rei, representante de Deus na Terra), metafísica (não há mais a ideia de Absoluto) e simbólica (o elemento de referência exterior à sociedade). O spleen resulta disso, e as flores - que na tradição se associavam à beleza, à perfeição, à contemplação - são agora o mal, como quando Baudelaire escreve que a criação foi a "queda de Deus" ou se se quiser, a modernidade é o progresso da técnica sem nenhum ideal de espírito, como se não houvesse mais espaço para o Bem.

Como interpretas o cenário político atual, de crises econômicas, recrudescimento da violência, intolerância ideológica, aumento da desigualdade e desrespeito aos direitos humanos ? E como as artes têm se posicionado em tal contexto ?

É muito difícil responder a estas questões, mas um começo de reflexão seria pensarmos em problemas combinados, desde a sociedade do espetáculo e a espetacularização da violência e na banalização do mal, o mimetismo de apropriação ou inveja mimética nos termos de René Girard, a universalização de uma educação medíocre e na indústria cultural, em suma, no quadro do desaparecimento do papel filosófico e existencial da cultura, no sentido humanista de valorização dos saberes literários e humanistas. A arte - quando autônoma, quando não é instrumento de dominação a serviço de uma causa - é o espaço da "transcendência" com respeito à imediatez da vida empírica e não reflexiva, é exercício do pensamento livre, quer dizer, ela pode exercer sua natureza crítica no sentido benjaminiano de "correto distanciamento" da facticidade e assim ela é promesse de bonheur em que a "ação é irmã do sonho". 
Como a indústria cultural, a aceleração do tempo e a arrogância capitalista contribuem para a "perda da experiência", da hospitalidade, da alteridade e da consciência histórica ? Nesse sentido o ato transgressivo, como engajamento político, pode ser frutífero ?

A aceleração do tempo, a cultura capitalista, o fetiche da inovação pela inovação, o desaparecimento da ideia de contemplação e a supervalorização da ação e do ativismo, desenvolvem uma cultura "maníaca", de onde o esporte ter tomado o lugar da Escola e ter-se desenvolvido uma indústria da euforia, em que tudo se converte em megashow, desde os cultos religiosos até a educação. Neste âmbito, com o fim da atenção concentrada ou imersão nas obras de arte, estabelece-se a dispersão, com o fim também do cuidado com o Outro, do respeito do Outro, lembrando que respeitar é re-spectare, é olhar de volta, é olhar de novo, é ter cuidado com o ver, é cuidar. Outra maneira de dizer que sem delicadeza não pode haver vida social e hospitalidade, acolhimento incondicional daquele que chega em nossa "casa" e que tudo desconhece do mundo estrangeiro, aquele que chega na condição de suplicante e está sem "pátria", aquele que perdeu o lugar de seu primeiro encontro com a vida e que quer ser recebido, a hospitalidade sendo o dever por excelência do humano.

\section{RESUMOS}

Nessa entrevista, a filósofa e escritora Olgária Matos interpreta a ideia de transgressão diante do atual cenário político e cultural. A autora discorre sobre experiências criativas, humanismo ocidental, autonomia das artes, direito à diferença, indústria cultural, bem como sobre a temporalidade e a arrogância no mundo capitalista. Olgária Matos é professora da Universidade de São Paulo e da Universidade Federal de São Paulo. É autora de Benjaminianas : cultura Capitalista e Fetichismo contemporâneo. São Paulo: UNESP, 2010 ; Contemporaneidades. São Paulo: Editora Lazuli, 2009 ; Discretas Esperanças : reflexões filosóficas sobre o mundo contemporâneo. São Paulo : Nova

Dans cet entretien, la philosophe et écrivaine Olgária Matos aborde l'idée de transgression sur la scène politique et culturelle actuelle. L'auteure évoque les expériences créatives, l'humanisme occidental, l'autonomie des arts, le droit à la différence, l'industrie culturelle, ainsi que la notion de précarité et l'arrogance qui caractérisent le monde capitaliste. Olgária Matos est professeure à l'Université de São Paulo et à l'Université fédérale de Sao Paulo. Elle est notamment l'auteure de "Benjaminianas : cultura Capitalista e Fetichismo contemporâneo." São Paulo: UNESP, 2010 ; "Contemporaneidades." São Paulo: Editora Lazuli, 2009; "Discretas Esperanças: reflexões filosóficas sobre o mundo contemporâneo." São Paulo : Nova Alexandria, 2006.

\section{ÍNDICE}

Mots-clés: Matos (Olgária), autonomie des arts, droit à la différence, transgression

Palavras-chave: Matos (Olgária), transgresão, autonomia das artes, direito a diferença 
AUTORES

GASPAR PAZ

UFES

ALINE MIKLOS

EFISAL-CRAL-EHESS 